\title{
Assessment of snowmelt runoff modelling and isotope analysis: a case study from the western Himalaya, India
}

\author{
Rajeev Saran AHLUWALIA, ${ }^{1 *}$ S.P. RAI, ${ }^{1}$ Sanjay K. JAIN, ${ }^{1}$ Bhishm KUMAR, ${ }^{2}$ \\ D.P. DOBHAL ${ }^{3}$ \\ ${ }^{1}$ National Institute of Hydrology, Roorkee, Uttarakhand, India \\ E-mail: raahluwalia05@gmail.com \\ ${ }^{2}$ International Atomic Energy Agency, Vienna, Austria \\ ${ }^{3}$ Wadia Institute of Himalayan Geology, Dehradun, Uttarakhand, India
}

\begin{abstract}
The major river systems of India, i.e. the Indus, Ganga and Brahmaputra river systems originating in the Himalayan region, are considered the lifeline of the Indian subcontinent. The main sources maintaining the flow of the Himalayan rivers are snow/glacial melt runoff, rainfall runoff and base flow. The Beas River originates from Beas Kund Glacier in the Himalayan region and flows down to join the Sutlej River, which is a tributary of the Indus River system. In the present study two approaches, namely hydrologic modelling and isotope analysis, have been applied to estimate the contribution of snow and glacier melt. Samples of streamflow, rainfall and snow for isotopic analysis were collected daily from April to September and weekly from October to March during 2010 and 2011. The isotope analysis of samples reveals that the snow/glacier melt contribution to the Beas River at Manali is $\mathbf{5 0} \%$ of the total flow during these 2 years. Snowmelt runoff modelling has been carried out using the SNOWMOD model, and the snow/glacier melt runoff contribution is calculated to be $52 \%$ of the total flow during the same period. These findings indicate that the results obtained from the two approaches are similar.
\end{abstract}

\section{INTRODUCTION}

Snow/glacier melt is a vital component of the streamflow for the Himalayan river system (Rai and others, 2009; Jain and others, 2011). Major Himalayan rivers receive substantial amounts of snow and glacier meltwater contribution during the summer, which ensures a year-round water supply used for various purposes. However, there are several studies indicating that most of these glaciers and snowpacks are retreating (Naithani and others, 2001; Dobhal and others, 2004; Hewitt, 2005; Kulkarni and others, 2005). Ageta and Kadota (1992) reported that $67 \%$ of glaciers in the Himalaya are retreating at a startling rate, and climate change has been identified as the major causal factor. Therefore, glacial melt will affect freshwater flow, with dramatic adverse effects on biodiversity, people and livelihoods and possible long-term implications for regional food security (Thomas and Rai, 2005).

However, no study has been carried out using isotopic analysis to estimate the snow/glacier melt contribution, which is very important for regulating the flow from the reservoirs, for estimating flood flow, for the design of hydraulic structures and for other water resource development activities in the Beas basin of the western Himalayan region. In order to estimate the contribution from snowmelt, here we attempt to characterize streamflow using a stableisotope technique as well as a modelling approach for the Beas basin up to Manali in the western Himalaya, India.

Stable-isotope tracers $\left(\delta^{18} \mathrm{O}, \delta^{2} \mathrm{H}\right)$ are known to be conservative, and, due to mixing processes, changes in concentration may occur with hillslopes. Studies carried out during the last few decades have established that stable oxygen and hydrogen isotope ratios provide useful tools for

*Present address: Centre of Glaciology, Wadia Institute of Himalayan Geology, Dehradun, Uttarakhand, India streamflow studies (Dinçer and Payne, 1971; Martinec and others, 1974; Behrens and others, 1979; Hooper and Shoemaker, 1986; Obradovic and Sklash, 1986; Maulé and Stein, 1990). These stable isotopes (expressed as ${ }^{18} \mathrm{O}$, ${ }^{2} \mathrm{H}$ ) in the streamflow of Himalayan rivers, namely the Ganga, Yamuna and Indus rivers, have been used successfully to study the characteristics of the rivers (Ramesh and Sarin; 1992; Dalai and others, 2002; Rai and others, 2010, 2011). Although a number of investigations have employed isotopic tracers, the use of isotopes to identify the contribution of base flow, snow/glacier melt and rain to the Himalayan rivers has received little attention.

In the present paper, a hydrological modelling (SNOWMOD) approach is employed to estimate the snow/glacier melt contribution, and the results are compared with those obtained with the isotope technique.

\section{STUDY AREA}

Two tributaries of the Beas River, originating from Beas Kund and Rohtang, pass at altitudes of 3505 and 3977 m, respectively, and meet at Palchan, which is $10 \mathrm{~km}$ above Manali. From a clear blue easy-flowing mountain river in the nonmonsoon period, the Beas River turns into a turbulent river during the monsoon. The river flows further to Manali, and another important tributary, Parvati, joins at Bhunter (Fig. 1). After traversing the hills, it enters Punjab and joins the Satluj River at Hari Ka Patan. This study focuses on the Beas basin up to the headwater region (Manali, western Himalaya).

The study area experiences a winter season (DecemberMarch) characterized by the occurrence of heavy snowfall (Fig. 2) at higher altitudes. The winter season is followed by the pre-monsoon season (April-June). The monsoon season usually commences by June and extends up to September, whereas the post-monsoon season during OctoberNovember is generally the driest with little rainfall. 


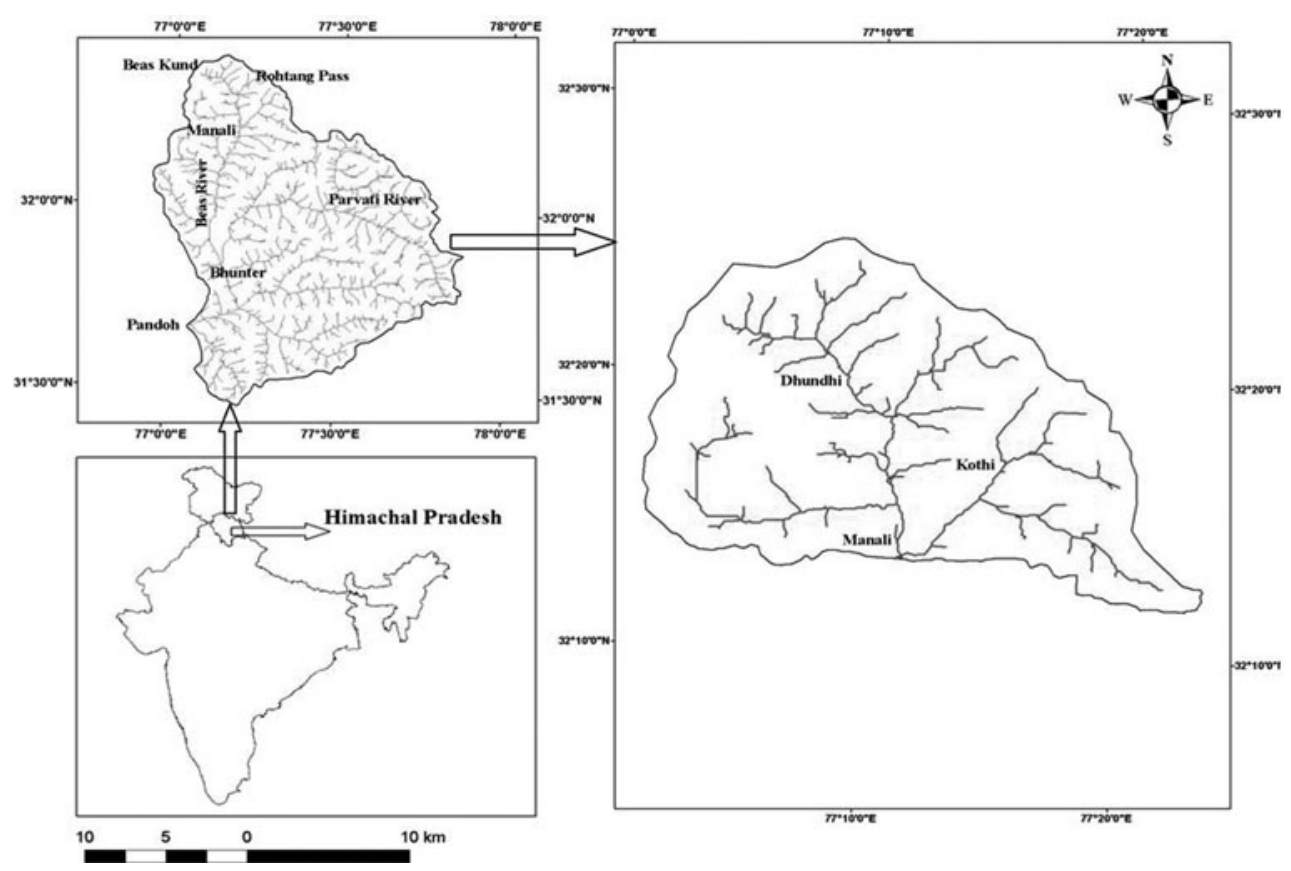

Fig. 1. Study area of Beas basin up to Manali.

\section{DATABASE PREPARATION}

\section{Sampling and analysis}

To investigate the isotopic signatures of the study river, samples of streamflow were collected daily and weekly from the study area from April 2010 to March 2011 and were analysed for $\delta^{18} \mathrm{O}$ and $\delta \mathrm{D}$. At higher altitudes the melting of snow and ice starts in April in the ablation period and continues up to October (Fig. 2). During this period, samples of streamflow and rain were collected daily at Manali for isotope analysis and twice each month for electrical conductivity measurements. The streamflow is sustained by the melting of snow and glacier during the ablation period and delivers the isotopic indices of snow and glacier. From October to April, the streamflow is low compared with the summer and the rainy season. For the winter season, samples of streamflow were collected weekly, whereas samples of rain and snow were collected as and when these events occurred in the season. For stable-isotope measurements, samples were collected in pre-cleaned $20 \mathrm{~mL}$ polypropylene bottles (Tarsons). The bottles were rinsed thoroughly with sample water at the study site, filled with water samples, tightly capped (to prevent evaporation and exchange with atmospheric moisture) and transferred to the laboratory for isotopic analyses.

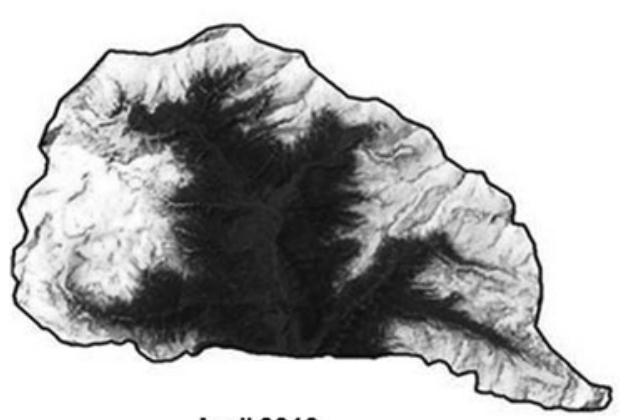

April 2010
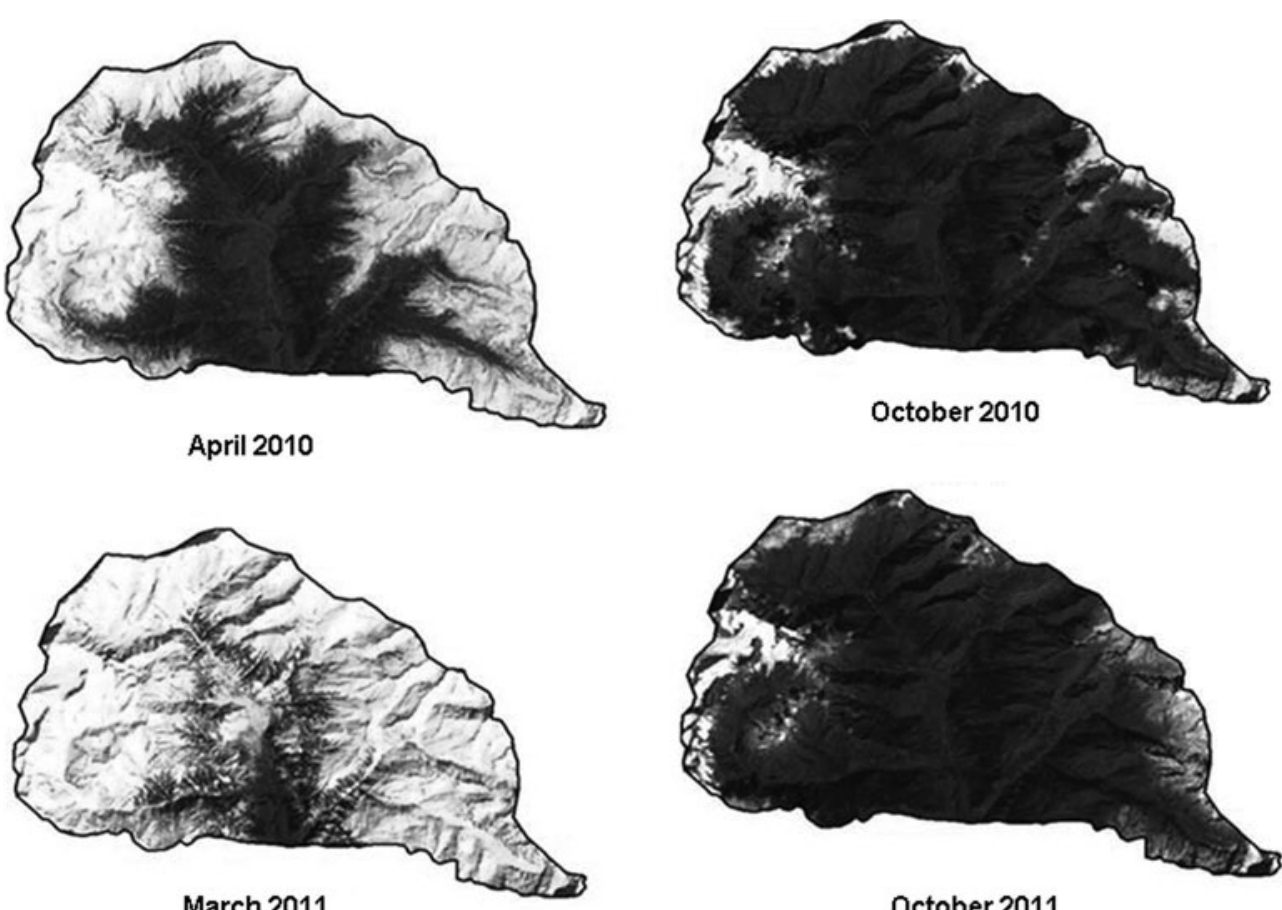

October 2011

Fig. 2. Seasonal snow variation of Beas basin up to Manali. 
The oxygen and hydrogen $\left(\delta^{18} \mathrm{O}\right.$ and $\left.\delta \mathrm{D}\right)$ isotope measurements were carried out using a Dual Inlet Isotope Ratio Mass Spectrometer (GV Instruments, UK) with automatic sample preparation units. For oxygen and hydrogen isotopes, $400 \mu \mathrm{L}$ water samples were taken and hokobeads were used as the catalyst. Along with each batch of samples, secondary standards developed with reference to primary standards (i.e. V-SMOW, SLAP, GISP) were also measured and the final $\delta$ values were calculated using a triple-point calibration equation. The overall precision, based on ten points of repeated measurements of each sample, was within $\pm 0.1 \%$ for $\delta^{18} \mathrm{O}$ and $\pm 1 \%$ for $\delta \mathrm{D}$.

\section{Digital elevation model}

For snowmelt runoff modelling, a digital elevation model (DEM) is required to handle various elevation zones. A DEM generated using the Advanced Spaceborne Thermal Emission and Reflection Radiometer (ASTER) sensor was used in this study. ASTER is an imaging instrument on board the Terra satellite launched in December 1999 as a part of NASA's Earth Observing System (EOS). ASTER resolution ranges from 15 to $90 \mathrm{~m}$ depending on the wavelength. The instrument records in three bands - the visible/near-infrared (VNIR), the shortwave infrared (SWIR) and the thermal infrared (TIR) - oriented on the nadir and looking backward. There are 14 spectral bands altogether spanning the visible and infrared spectra and so the sensor is susceptible to cloud cover and cannot record images at night. Because of its offnadir sensor pointing capability, ASTER can collect the stereo pairs necessary to generate high-resolution DEMs (using bands $3 \mathrm{~N}$ and $3 \mathrm{~B}$ ). The ASTER on board the Terra satellite has produced $30 \mathrm{~m}$ resolution elevation data. There is a fairly complete coverage of the Earth at this high resolution and the data are free.

\section{Hydrometeorological data}

In this study hydrological modelling was carried out for estimation of snowmelt runoff. For this purpose, hydrometeorological data were collected at Manali from Bhakra Beas Management Board (BBMB). For this study, the data from 2004 to 2011 were used to study the seasonal variation of streamflow and snow/glacier melt contribution.

\section{Snow-cover area}

Snow-cover area (SCA) maps, required in snowmelt runoff modelling, have been prepared using satellite data. Moderate Resolution Imaging Spectroradiometer (MODIS) snow products were selected to calculate the percentage of SCA in the study area. The MODIS/Terra snow-cover 8 day L3 global $500 \mathrm{~m}$ grid (MOD10A2) used for the study contains the data field for maximum snow-cover extent over an 8 day repeated period (Hall and others, 2006, updated weekly) and has a resolution of $\sim 500 \mathrm{~m}$ covering the Beas basin. MODIS data from 2004 to 2009 were downloaded from www.wist. echo.nasa.gov.in, which is now renamed as http://reverb. echo.nasa.gov/reverb. SCA for the study area was extracted from these MODIS images.

\section{METHODOLOGY}

\section{Isotopic approach}

In this approach, two- and three-component models were applied to separate out the streamflow component. A twocomponent mixed model was applied for the pre- and post-monsoon season when streamflow is contributed by two components, i.e. base flow (groundwater) and snow/ glacier meltwater. The recorded rainfall was negligible for this period. A three-component mixed model was employed for the monsoon season (July-September) when rainfallderived runoff also contributes to streamflow.

The $\delta^{18} \mathrm{O}$ of the streamflow was found to be different during the non-rainy months (October-June) due to a variable contribution from snow/glacier melt. In order to measure the changes in the isotopic composition of the streamflow, sampling of the streamflow, snow and groundwater (hand-pump and springs) was carried out during the whole year. The water-balance equation can be written as

$$
Q_{\mathrm{t}}=Q_{\mathrm{sm}}+Q_{\mathrm{gw}}
$$

where $Q$ is the discharge component and subscripts $\mathrm{t}$, sm and gw represent total river flow, snow/ice melt and runoff, respectively. Similarly, the isotopic-balance equation can be written as

$$
\delta_{\mathrm{t}} Q_{\mathrm{t}}=\delta_{\mathrm{sm}} Q_{\mathrm{sm}}+\delta_{\mathrm{gw}} Q_{\mathrm{gw}},
$$

where $\delta=\left[\left(R_{\text {sample }} / R_{\text {std }}\right)-1\right] * 10^{3} \%$.

From Eqns (1) and (2), we get

$$
Q_{\mathrm{sm}}=Q_{\mathrm{t}}\left(\delta_{\mathrm{t}}-\delta_{\mathrm{gw}}\right) /\left(\delta_{\mathrm{sm}}-\delta_{\mathrm{gw}}\right) .
$$

Using Eqn (3), the snow/glacier meltwater component can be separated.

During the monsoon months, the Beas River receives contributions from snow/glacier melt, groundwater (subsurface water) and rainfall-derived runoff in the total streamflow. Hence, a three-component mixing model was derived for the Beas River basin to separate out the contribution from different components. The isotopic composition $\left(\delta^{18} \mathrm{O}\right)$ and electrical conductivity of snow/ice melt, rainfall and groundwater components were used along with the streamflow for the derivation of the model given below:

$$
\begin{gathered}
Q_{\mathrm{gw}}+Q_{\mathrm{gm}}+Q_{\mathrm{R}}=Q \\
Q_{\mathrm{gw}} \delta_{\mathrm{gw}}+Q_{\mathrm{gm}} \delta_{\mathrm{gm}}+Q_{\mathrm{R}} \delta_{\mathrm{R}}=Q \delta_{Q} \\
Q_{\mathrm{gw}} C_{\mathrm{gw}}+Q_{\mathrm{gm}} C_{\mathrm{gm}}+Q_{\mathrm{R}} C_{\mathrm{R}}=Q C_{Q},
\end{gathered}
$$

where $Q, Q_{R}, Q_{g w}$ and $Q_{g m}$ are the total river discharge, surface runoff, groundwater and snow/glacier meltwater contribution $\left(\mathrm{m}^{3} \mathrm{~s}^{-1}\right)$ and $\delta_{\mathrm{Q}}, \delta_{\mathrm{R}}, \delta_{\mathrm{gw}}$ and $\delta_{\mathrm{gm}}$ are the corresponding $\delta^{18} \mathrm{O}$ values, respectively.

From Eqns (4) and (5)

$$
Q_{\mathrm{R}}=\frac{Q\left(\delta_{\mathrm{Q}}-\delta_{\mathrm{gm}}\right)-Q_{\mathrm{gw}}\left(\delta_{\mathrm{gw}}-\delta_{\mathrm{gm}}\right)}{\left(\delta_{\mathrm{R}}-\delta_{\mathrm{gm}}\right)} .
$$

Now from Eqns (4), (5) and (7), we get

$$
Q_{\mathrm{gw}}=Q\left[\frac{\left(C_{Q}-C_{\mathrm{gm}}\right)-\left(C_{\mathrm{R}}-C_{\mathrm{gm}}\right)\left\{\frac{\left(\delta_{\mathrm{Q}}-\delta_{\mathrm{gm}}\right)}{\left(\delta_{\mathrm{R}}-\delta_{\mathrm{gm}}\right)}\right\}}{\left(C_{\mathrm{gw}}-C_{\mathrm{gm}}\right)-\left(C_{\mathrm{R}}-C_{\mathrm{gm}}\right)\left\{\frac{\left(\delta_{\mathrm{g}}-\delta_{\mathrm{gm}}\right)}{\left(\delta_{\mathrm{R}}-\delta_{\mathrm{gm}}\right)}\right\}}\right] .
$$

\section{Modelling approach}

The snowmelt model (SNOWMOD) has been applied to estimate the snowmelt runoff contribution to the Beas River (Jain, 2001; Singh and Jain, 2002). SNOWMOD is designed to simulate daily streamflow for mountainous basins having contributions from both snowmelt and rainfall. The generation of streamflow involves primarily the determination of the input derived from snowmelt and rain and its transformation into runoff. For simulating the streamflow, the 

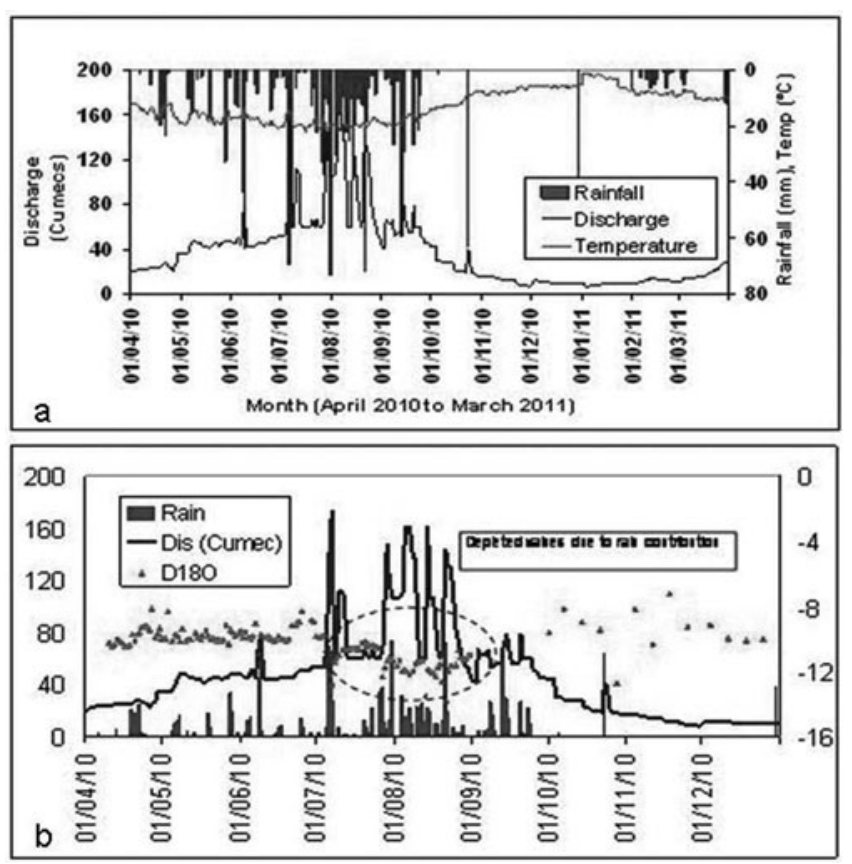

Fig. 3. Variation of (a) streamflow and (b) its $\delta^{18} \mathrm{O}$ composition during 2010/11.

basin is divided into a number of elevation zones, and various hydrological processes relevant to snowmelt and rainfall runoff are evaluated for each zone. Six different altitudinal zones are extracted from the ASTER DEM for Beas basin up to Manali. The model deals with snowmelt and rainfall runoff by performing the following three operations at each time-step: (1) available meteorological data are extrapolated to the different elevation zones; (2) rates of snowmelt and/or rainfall are calculated separately at different points; and (3) snowmelt runoff from the SCA and rainfall runoff from the snow-free area (SFA) are integrated. These components are routed separately with proper accounting of base flow at the outlet of the basin. The model optimizes the parameters used in routing of the snowmelt runoff and rainfall runoff. Details of this model are given in earlier studies (Jain, 2001; Singh and Jain, 2002).

\section{RESULTS AND DISCUSSIONS}

The hydrograph of the Beas River at Manali (Fig. 3a) shows the variation in streamflow due to the varied contribution of different components in a year. The minimum flow was recorded during the winter months of December and January when rainfall and snow/glacier melt are negligible and the streamflow is sustained only by the base flow. The hydrograph shows that streamflow starts to increase in April due to the increased contribution of snow/glacier meltwater from lower altitudes. This increasing trend continues until June, i.e. prior to the onset of the monsoon season. This clearly indicates the contribution of snow/glacier meltwater increasing in streamflow due to the increase in air temperature (Fig. 3a). The maximum streamflow was observed during the monsoon months (July-September) and the multiple peaks on the hydrograph correspond to highintensity rain events.

The $\delta^{18} \mathrm{O}$ of river water varied between a minimum of $-11.96 \%$ in August and a maximum of $-10.28 \%$ in April. During July, August and September, the river becomes suddenly more depleted due to isotopically depleted rainfall events in the catchment, which indicates a quick rainfallrunoff contribution to the river. During October, November and December (a period of negligible rain and snow/glacier meltwater), river $\delta^{18} \mathrm{O}$ shows a trend of isotopic enrichment due to an increase in the contribution of groundwater compared with rainfall-derived runoff and snow/glacier melt contribution. Therefore, the $\delta^{18} \mathrm{O}$ value of the river for November is taken as characteristic of subsurface/groundwater, which is $-11.44 \%$. The $\delta^{18} \mathrm{O}$ of snow is derived from the average value of all snow events, which is $-10.05 \%$. During the summer months (April-June) the river shows enriched $\delta^{18} \mathrm{O}$ values, due to melting of the snow as a result of increased air temperature. The variation in river $\delta^{18} \mathrm{O}$ is shown in Figure $3 \mathrm{~b}$. The analysis of $\delta^{18} \mathrm{O}$ and $\delta \mathrm{D}$ data for streamflow, snow and rain (Fig. $4 \mathrm{a}-\mathrm{C}$ ) gives a high coefficient of correlation, which indicates good performance of the isotopic analysis. The meteoric waterlines developed for river, snow and rain, respectively, are

$$
\begin{aligned}
& \delta \mathrm{D}=8.39 * \delta^{18} \mathrm{O}+21.87 \\
& \delta \mathrm{D}=8.69 * \delta^{18} \mathrm{O}+22.94 \\
& \delta \mathrm{D}=8.00 * \delta^{18} \mathrm{O}+9.86 .
\end{aligned}
$$

As can be seen from Eqns (9) and (10), the river isotopic composition is close to the snow isotopic composition, indicating a significant contribution of snow/glacier meltwater to the streamflow. The snow/glacier meltwater contribution estimated using a two-component mixing model shows that the contribution varies from 26\% (October) to $83 \%$ (April) of the total streamflow during the pre- and postmonsoon months, respectively.

A three-component mixing model is used for July, August and September (the monsoon season) when the river receives runoff from rainfall along with base flow and snow/glacier meltwater. The rainfall runoff contribution varied and was $16 \%, 26 \%$ and $21 \%$ in July, August and September, respectively. The base-flow contribution ranged from $17 \%$ in April to $\sim 100 \%$ in November (Fig. 5). The estimated contribution of snow/glacier melt runoff varied between $32 \%$ (September) and $62 \%$ (July) of the total streamflow during this period. On average, the annual snow/ glacier meltwater contribution to streamflow is $50 \%$ of the total annual runoff of the Beas River at Manali during the study period 2010-11.

The snowmelt runoff model (SNOWMOD) has been applied for simulating the daily flows for the Beas River at Manali. The observed data for 2004/05 and 2005/06 have been considered in the model calibration, whereas 2006/ 07, 2008/09 and 2010/11 have been considered in the model validation. The efficiency of the model has been computed based on the daily simulated and observed flow values of 5 years. The values of the model efficiencies were $82 \%, 80 \%, 78 \%, 81 \%$ and $81 \%$ for the Beas River during 5 years. The performance of the model in preserving the runoff volume of the entire year has been tested based on the criterion computed as the percentage difference in the observed and simulated runoff. The model has the capability to separate out the contributions of rainfall, snow/glacier melt and base flow from the simulated flows. From the hydrograph, as shown in Figure 6, it has been observed that the model simulated the daily flows reasonably well, generally showing a good match with the 

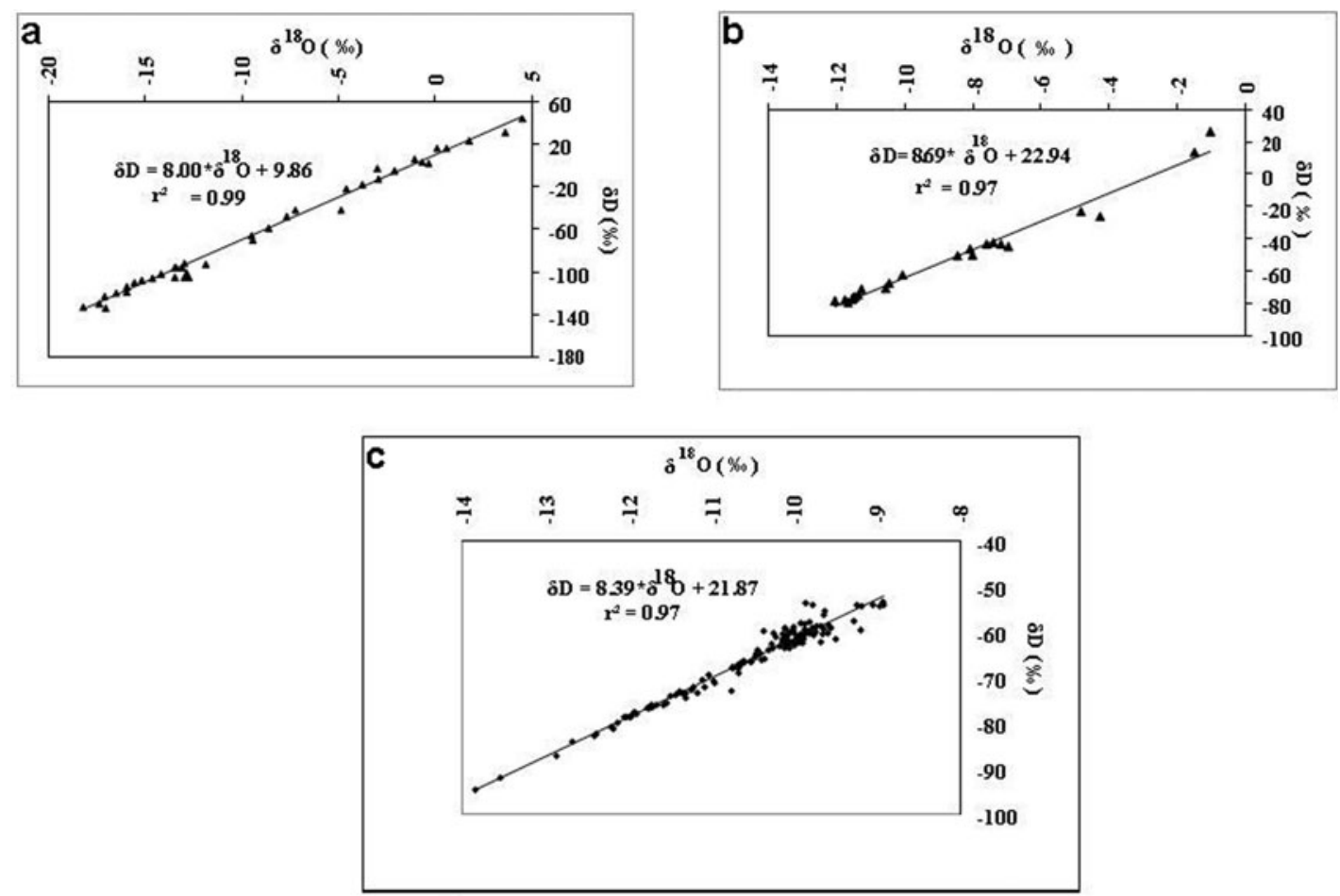

Fig. 4. Isotopic characteristics of (a) rain, (b) snow and (c) streamflow.

Table 1. Difference in volume, model efficiency and contributions of rain, snow/glacier melt and groundwater

\begin{tabular}{lccccc}
\hline Year & $\begin{array}{c}\text { Difference in } \\
\text { volume } \\
\%\end{array}$ & $\begin{array}{c}\text { Model } \\
\text { efficiency } \\
\%\end{array}$ & Rain & Snow & Groundwater \\
& $\%$ & $\%$ & $\%$ \\
\hline $2004 / 05$ & 5.62 & 82 & 5.8 & 52 & 42.2 \\
$2005 / 06$ & 6.52 & 80 & 6.0 & 54 & 40.0 \\
$2006 / 07$ & 5.41 & 78 & 6.4 & 52 & 41.6 \\
$2008 / 09$ & 5.16 & 81 & 7.0 & 51 & 42.0 \\
$2010 / 11$ & 6.51 & 81 & 6.1 & 52 & 41.9 \\
\hline
\end{tabular}

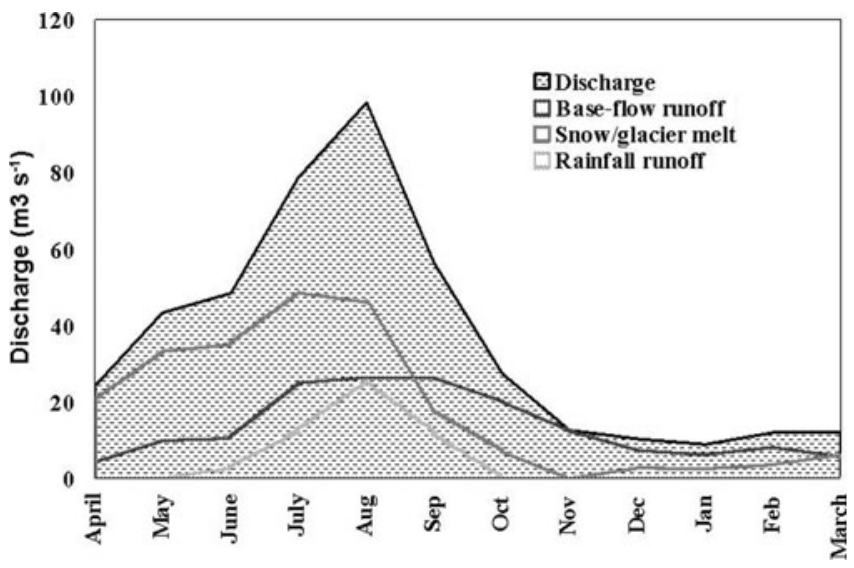

Fig. 5. Surface runoff, snow/glacier melt, base-flow and rainfall components separated out using isotopic signature of stream water, precipitation and groundwater on the basis of daily sampling data obtained during 2010/11 at Manali. observed daily flows. The trends and peaks of the daily flow hydrographs for the whole year are also well simulated by the model. The percentage difference in volume, model efficiency and contributions of rain, snow and base flow are summarized in Table 1 . In the Beas River at Manali the estimated contribution of snow/glacier meltwater is $52 \%$, $54 \%, 52 \%, 51 \%$ and $52 \%$ of the total streamflow in the years 2004/05, 2005/06, 2006/07, 2008/09 and 2010/11, respectively, with an average of $52 \%$.
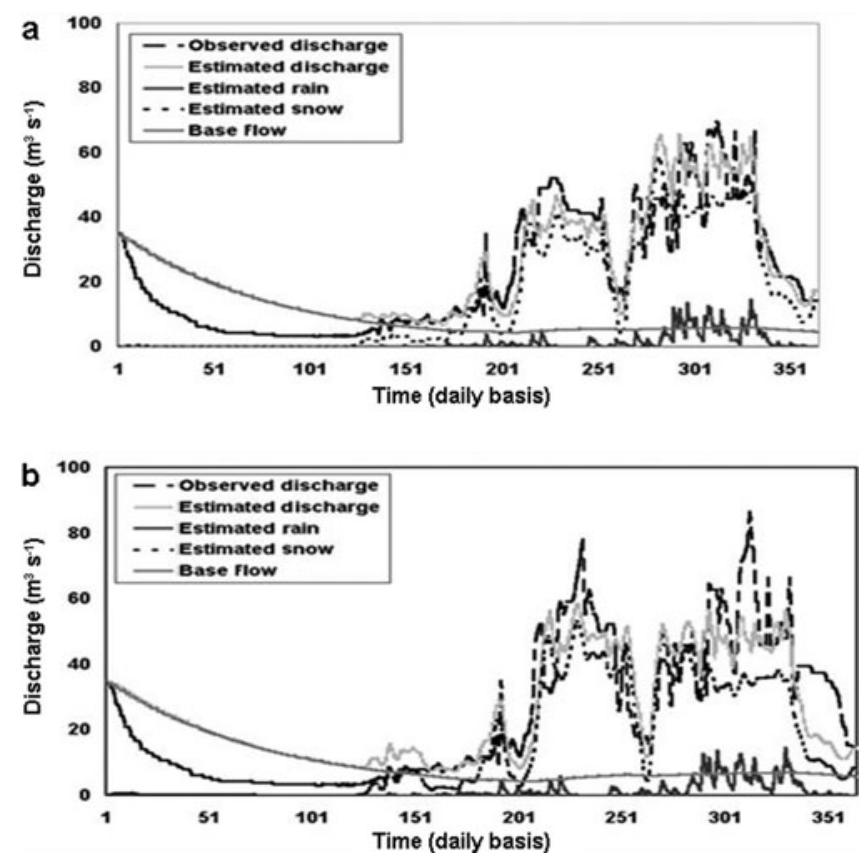

Fig. 6. Observed and simulated daily streamflow for the Beas River at Manali for (a) 2005/06 and (b) 2008/09. 


\section{CONCLUSION}

Snow/glacier melt runoff contribution generally starts in April in the Himalayan basins. From April to June, snowmelt runoff is the predominant source of runoff, while from July to September rainfall as well as snow/glacier melt contributes to runoff. Therefore high peaks in runoff are observed during this period due to rainfall contribution. During the winter, base flow contributes to streamflow. In this study, these three components have been separated out using two approaches, namely a modelling approach and an isotopic approach. The results from the isotopic approach reveal that the snow/ glacier melt contribution to the streamflow is $50 \%$, whereas from the modelling approach it is estimated to be $52 \%$. In other words, it can be concluded that the results obtained using the isotopic approach are a verification of the results obtained using the modelling approach.

\section{ACKNOWLEDGEMENTS}

We thank the Director of the National Institute of Hydrology, Roorkee, India, for valuable guidance and support during this study. We also thank the Bhakra Beas Management Board (BBMB), Nangal, India, for providing the meteorological data used in this study.

\section{REFERENCES}

Ageta Y and Kadota T (1992) Predictions of changes of glacier mass balance in the Nepal Himalaya and Tibetan Plateau: a case study of air temperature increase for three glaciers. Ann. Glaciol., 16, 89-94

Behrens $\mathrm{H}$ and 6 others (1979) Models for the runoff from a glaciated catchment area using measurements of environmental isotope contents. In Isotope Hydrology 1978. Proceedings of the International Symposium on Isotope Hydrology, 19-23 June, 1978, Neuherberg, Germany, Vol. 2. International Atomic Energy Agency, Vienna, 829-846

Dalai TK, Bhattacharya SK and Krishnaswami S (2002) Stable isotopes in the source waters of the Yamuna and its tributaries: seasonal and altitudinal variations and relation to major cations. Hydrol. Process., 16(17), 3345-3364 (doi: 10.1002/hyp.1104)

Dinçer T and Payne BR (1971) An environmental isotope study of the south-western Karst region of Turkey. J. Hydrol., 14(3-4), 233-258 (doi: 10.1016/0022-1694(71)90037-0)

Dobhal DP, Gergan JG and Thayyen RJ (2004) Recession and morphogeometrical changes of Dokriani glacier (1962-1995), Garhwal Himalayas, India. Current Sci., 86(5), 692-696
Hall DK, Riggs GA and Salomonson VV (2006) MODIS snow and sea ice products. In Gao W, Kafatos M, Murphy RE and Salomonson VV eds. Earth science satellite remote sensing, vol. 1: Science and instruments. Tsinghua University Press, Beijing/ Springer-Verlag, Berlin

Hewitt K (2005) The Karakoram anomaly? Glacier expansion and the 'elevation effect', Karakoram Himalaya. Mt. Res. Dev., 25(4), 332-340 (doi: 10.1659/0276-4741(2005)025[0332:TKAGEA]2.0.CO;2)

Hooper RP and Shoemaker CA (1986) A comparison of chemical and isotopic hydrograph separation. Water Resour. Res., 22(10), 1444-1454 (doi: 10.1029/WR022i010p01444)

Jain SK (2001) Snowmelt runoff modeling and sedimentation studies in Satluj basin using remote sensing and GIS. (PhD thesis, University of Roorkee)

Jain SK, Rai SP and Ahluwalia RS (2011) Stream flow modelling of Beas River at Manali, Himachal Pradesh. In Proceedings of National Conference on Recent Advances in Civil Engineering (RACE-2011), 14-16 October 2011, Varanasi, U.P., India. Baranas Hindu University, Varanasi, U.P., 286-289

Kulkarni AV, Rathore BP, Mahajan S and Mathur P (2005) Alarming retreat of Parbati glacier, Beas basin, Himachal Pradesh. Current Sci., 88(11), 1844-1850

Martinec J, Siegenthaler U, Oeschger H and Tongiorgi E (1974) New insights into the runoff mechanism by environmental isotopes. In Proceedings of a Symposium on Isotope Techniques in Groundwater Hydrology, 11-15 March 1974, Vienna, Austria. International Atomic Energy Agency, Vienna, 129-144

Maulé CP and Stein J (1990) Hydrologic flow path definition and partitioning of spring meltwater. Water Resour. Res., 26(12), 2959-2970 (doi: 10.1029/WR026i012p02959)

Naithani AK, Nainwal HC, Sati KK and Prasad C (2001) Geomorphological evidences of retreat of the Gangotri glacier and its characteristics. Current Sci., 80(1), 87-94

Obradovic MM and Sklash MG (1986) An isotopic and geochemical study of snowmelt runoff in a small Arctic watershed. Hydrol. Process., 1(1), 15-30 (doi: 10.1002/hyp. 3360010104)

Rai SP, Kumar B and Singh P (2009) Estimation of contribution of southwest monsoon rain to Bhagirathi River near Gaumukh, western Himalayas, India, using oxygen-18 isotope. Current Sci., 97(2), 240-245

Ramesh R and Sarin MM (1992) Stable isotope study of the Ganga (Ganges) river system. J. Hydrol., 139(1-4), 49-62 (doi: 10.1016/0022-1694(92)90194-Z)

Singh Pand Jain SK (2002) Snow and glacier melt in the Satluj River at Bhakra Dam in the western Himalaya region. Hydrol. Sci. J., 47(1), 93-106

Thomas JK and Rai SC (2005) An overview of glaciers, glacier retreat and subsequent impacts in Nepal, India and China. Nepal Programme, WWF, Kathmandu 